\title{
0 gerenciamento de redes sociais digitais como possibilidade estratégica na comunicação pública: o caso do Instituto Federal do Rio de Janeiro
}

The management of digital social networks as a strategic possibility in public communication: The Federal Institute of Rio de Janeiro case

Juliana Caroline Alves dos Santos Fernandes

Mestra em Gestão e Estratégia em Negócios

Instituto Federal de Educação, Ciência e Tecnologia do Rio de Janeiro

juliana.santos@ifrj.edu.br

Fávia Luzia Oliveira da Cunha Galindo

Doutora em Ciências Sociais em Desenvolvimento, Agricultura e Sociedade

Universidade Federal Rural do Rio de Janeiro

flaviagalindo@uol.com.br

\section{Resumo}

Elaborado a partir de um estudo de caso realizado no Instituto Federal do Rio de Janeiro, este trabalho associa teoria e prática de temas da Comunicação Pública e da Gestão de Plataformas de Redes Sociais, com o objetivo principal de analisar a produção estratégica de conteúdo nas Redes Sociais Digitais oficiais da Instituição, entre os anos de 2014 e 2018. Para isso, verificou-se especificamente como os conceitos de interatividade, conteúdo e monitoramento dos dados foram empregados a partir das definições de Comunicação Pública. O estudo de caso considerou o ambiente digital do Instituto, mapeando as plataformas por ele usadas e identificando seus perfis oficiais. Como técnicas de coleta de dados, optou-se pela entrevista e pela observação participante. Ao todo, foram realizadas sete entrevistas, sendo os sujeitos da pesquisa servidores e estagiários (todos da Comunicação), responsáveis por gerenciar as páginas oficiais nas Redes Sociais Digitais do Instituto e por criar seu conteúdo. Posteriormente à coleta dos dados, empregou-se a técnica da análise de conteúdo, por meio da qual os resultados mostraram, em razão do uso equivocado das plataformas, uma baixa interatividade nas Redes Sociais Digitais da Instituição e pouco diálogo entre elas e os usuários. Embora o monitoramento de dados ainda seja insuficiente, concluiu-se que, além de a produção de conteúdo durante esse recorte temporal ter sido feita sob demanda e sem planejamento, a ausência de uma Política de Utilização de Redes Sociais Digitais atrelada à Política Institucional do Instituto foi um grande limitador do trabalho da Comunicação Organizacional, sobretudo no gerenciamento de suas Redes Sociais Digitais.

Palavras-chave

Comunicação Pública. Mídias Sociais. Redes Sociais Digitais.

\section{Abstract}

Elaborated from a case study accomplished in the Federal Institute of Rio de Janeiro, this work associates theory and practice with themes of Public Communication and Management of Social Networking Platforms. The researchers analyzed the strategic production of content on the Institution's official Digital Social Networks between 2014 and 2018. They specifically verified how the concepts of interactivity, content and data monitoring were used from the Public Communication definitions. The case 
study considered the Institute's digital environment, mapping the platforms it used and identifying its official profiles. As data collection techniques, an interview and participant observation were chosen. In total, seven interviews were conducted, being that the research subjects, servers and interns (all of the Communication), responsible for managing the official pages on the Institute's Digital Social Networks and for creating their content. After data collection, the content analysis technique was used, and the results showed low interactivity in the Institution's Digital Social Networks and little dialogue between them and users, probably due to the misuse of platforms. Although data monitoring is still insufficient, it was concluded that in addition to the content production had been made on-demand, without planning and with record time, the absence of a Policy for the Use of Digital Social Networks linked to the Institute Institutional Policy was a major limiter in the work of Organizational Communication, especially in the management of its Digital Social Networks.

\section{Keywords}

Public Communication. Social Media. Digital Social Media.

\section{INTRODUÇÃO}

Com o avanço da Tecnologia da Informação e Comunicação (TIC) e a criação da internet, a Comunicação Organizacional e os profissionais que com ela trabalham precisaram adaptar-se a essas mudanças e usar as mídias sociais como um meio de se posicionarem estrategicamente (CORRÊA, 2009). Com esse pano de fundo, "As mídias sociais tornaram-se uma ferramenta importante para as organizações, incluídas as instituições públicas, que passaram a utilizar essas mídias como forma para atender, prestar contas à sociedade e divulgar informações a um custo reduzido." (MARQUES; DELBARD, 2015, p.11). Houve, então, a necessidade de que os responsáveis pelo gerenciamento das mídias sociais compreendessem o comportamento dos cidadãos no meio digital, o que requer planejamento de ações com base nas informações coletadas.

É importante ressaltar que, ao se optar pelas mídias sociais no âmbito da gestão pública, deve-se considerar todas as prerrogativas consonantes com os conceitos da Comunicação Pública (CP). Para Brandão (2012), a CP não tem a sua definição plenamente consolidada, todavia ela "[...] deve incluir, necessariamente, todos os atores sociais que integram a esfera pública para debater e formular propostas de ações ou de políticas que beneficiem toda a sociedade." (MATOS, 2012, p. 45). Sobretudo, deve-se entender que uma instituição não atinge seus objetivos organizacionais sem ter com os seus públicos um relacionamento estratégico (PEREIRA; BORGES, 2012), sempre fundamentado nos princípios da Administração Pública, para que, assim, o conteúdo produzido alcance eficazmente o cidadão.

Dentre as possibilidades de utilização das mídias sociais como estratégia de interatividade entre a Administração Pública e o cidadão, destaca-se a abrangência das Redes Sociais Digitais (RSDs), que, conforme Henriques e Sant'ana (2015), permitem uma aproximação entre governo e sociedade, tornando o processo mais interativo e participativo. Corroborando com esses autores, Recuero $(2009$, p. 26) acrescenta o seguinte:

Rede social é gente, é interação, é troca social. É um grupo de pessoas, compreendido através de uma metáfora de estrutura, a estrutura de rede. [...] Assim, dizemos que essas redes proporcionaram mais voz às pessoas, mais construção de valores e maior potencial de espalhar informações. [...] Esses valores são chamados capital social. São pessoas que estão utilizando a Internet para ampliar suas conexões e construir um espaço mais democrático, mais amplo, mais plural e, com isso, gerando valores como reputação, suporte social, acesso às informações etc. 
Desse modo, o uso das RSDs tem sido cada vez mais frequente na Administração Pública - em diferentes esferas e áreas de atuação - conforme apontam pesquisas sobre o assunto. Dentre esses estudos, destaca-se o de Farranha et al. (2014), que analisou a utilização de específicas RSDs como ferramentas de florescimento de uma cultura democrática no âmbito do Ministério do Desenvolvimento Agrário, Secretaria Especial de Promoção da Igualdade Racial e Secretaria Especial de Mulheres. Evidencia-se também o estudo de Farranha e Santos (2015) que investigou a utilização das RSDs como ferramentas de difusão da informação institucional por meio do caso da Controladoria-Geral da União (CGU).

No âmbito da Educação Pública, o uso das RSDs igualmente tem se difundido, o que contribui com o ensino e a aprendizagem - pois, conforme Capobianco (2010), tais ferramentas oferecem recursos para potencializar esses processos, abrindo novas possibilidades para complementar o ensino formal. Além disso, influencia na maneira como as instituições publicizam suas ações e possibilita mais uma forma de interatividade com os seus públicos.

Nesse sentido, as instituições de ensino pertencentes à Rede Federal de Educação Profissional e Tecnológica ${ }^{1}$ - cuja necessidade legal é manter um relacionamento transparente com a sociedade referente às atividades de ensino, pesquisa e extensão (BRASIL, 1996; DELORS, 2010) - também têm utilizado as RSDs como ferramenta estratégica no processo de disseminação da informação institucional.

Diante disso, alguns questionamentos são suscitados no que se refere especificamente ao Instituto Federal de Educação, Ciências e Tecnologia do Rio de Janeiro (IFRJ): "As RSDs do IFRJ são utilizadas com base nos conceitos de CP? São as RSDs consideradas ferramentas estratégicas de maximização da imagem institucional? Há interatividade entre a instituição e seus públicos com o uso das RSDs? Os conteúdos são produzidos estrategicamente? Como é feito o monitoramento dos dados?". Terra (2015) nos diz que é preciso identificar cada público de uma organização para compreender quem são os responsáveis pela curadoria de conteúdo, os embaixadores da marca, os críticos, os insatisfeitos, entre outros, e, após essa análise, definir estratégias de comunicação (digitais ou não) para estreitar o relacionamento entre a instituição e seus diversos públicos.

No IFRJ, cabe à Coordenação-Geral de Comunicação Social (CGcom) o papel de comunicar as ações institucionais aos públicos internos e externos, por meio do gerenciamento dos canais de comunicação disponíveis, no qual estão incluídas as RSDs oficiais da Instituição. Ressalta-se que, a princípio, o gerenciamento de RSD's no IFRJ se resumiu apenas a produção de conteúdo com a finalidade principal de comunicar aos seus diversos públicos as ações desenvolvidas pela instituição. É importante contextualizar que, diante do cenário de contingenciamento e cortes no orçamento do Governo Federal, a CGcom do IFRJ² tem bus-

\footnotetext{
${ }^{1}$ Criada em 2008 pela Lei no 11.892, de 29 de dezembro, a Rede Federal de Educação Profissional, Científica e Tecnológica constituiu-se em um marco na ampliação, interiorização e diversificação da educação profissional e tecnológica no país. Até dezembro de 2018, era composta por 38 Institutos Federais, dois Centros Federais de Educação Tecnológica (Cefet), a Universidade Tecnológica Federal do Paraná (UTFPR), 22 escolas técnicas vinculadas às universidades federais e o Colégio Pedro II. Considerando os respectivos campi associados a essas instituições federais, tem-se ao todo 661 unidades distribuídas entre as 27 unidades federativas do país. Disponível em: http://portal.mec.gov.br/rede-federal-inicial/. Acesso: 13/07/2020.

${ }^{2}$ Conforme Regimento Geral do IFRJ, além da CGcom da Reitoria, vinculada ao Gabinete do Reitor, os campi do IFRJ devem ser dotados de suas próprias assessorias de comunicação.
} 
cado alternativas à propaganda convencional que sejam de menor custo e que proporcionem novos meios de interação com seus públicos. Uma das opções de maior impacto é fortalecer utilização de plataformas de RSDs, tais como Facebook, Instagram, YouTube e Twitter, que surgem como uma forma prática e gratuita de divulgação institucional, podendo ser realizada pela equipe interna de Comunicação, sem a necessidade de processo licitatório.

Dessa maneira, este trabalho tem como objetivo principal analisar, entre os anos de 2014 e 2018, a produção estratégica de conteúdo nas RSDs oficiais do IFRJ - especificamente como os conceitos de interatividade, conteúdo e monitoramento dos dados são empregados a partir das definições de CP. Para isso, optou-se por desenvolver uma pesquisa de natureza aplicada e de cunho qualitativo, que utiliza o estudo de caso como procedimento investigativo.

\section{METODOLOGIA}

Este trabalho se baseou nas premissas de uma pesquisa qualitativa, em que se adotou o estudo de caso como procedimento investigativo. Segundo Creswell (2014), esse método é ideal quando se pretende discutir os comportamentos de diferentes grupos de indivíduos interconectados no lócus onde ocorre o fenômeno que se quer observar.

Segundo Duarte (2015), o estudo de caso - habitualmente utilizado em pesquisas qualitativas - não representa uma amostragem e tem o objetivo de fazer uma generalização analítica de teorias, e não de particularizá-las. Para esta pesquisa, que considera o IFRJ como objeto de investigação, o estudo de caso foi empregado com o propósito de aumentar o nível de compreensão da pesquisadora sobre os objetivos a serem investigados neste trabaIho, elencados a partir de categorias analíticas concernentes aos conceitos atrelados ao uso das RSDs, a saber: interatividade; conteúdo e monitoramento de dados. Mais especificamente, o estudo de caso foi desenvolvido com o objetivo de entender como os campi do IFRJ usam as RSDs e fazer um levantamento de quais plataformas são usadas, além de identificar como deve ser, em consonância com os conceitos da CP, a Política de Utilização de Redes Sociais Digitais na Instituição.

De acordo com Yin (2007), o estudo de caso possibilita, conforme a natureza do objeto de pesquisa, a aplicação de diferentes técnicas de coleta de dados, como, por exemplo, entrevistas, observações diretas e análise documental, podendo essas técnicas ser combinadas ou não. Para este trabalhou, optou-se pela entrevista e pela observação participante como técnicas de coleta de dados.

Os sujeitos da pesquisa são servidores e estagiários de Comunicação responsáveis pelo gerenciamento e pela criação de conteúdo para as páginas oficiais nas RSDs do IFRJ, atuantes tanto na Reitoria quanto nos campi ${ }^{3}$. Foram realizadas sete entrevistas, as quais ocorreram individualmente (em dias e horários acordados com antecedência), sendo gravadas com a autorização dos entrevistados - que receberam e assinaram o Termo de Consentimento Livre e Esclarecido (TCLES) -, anotadas em fichas e, posteriormente, transcritas em um total de 55 páginas. Optou-se por um roteiro semiestruturado para garantir flexibilidade de acordo com as especificidades de cada entrevistado/campus.

\footnotetext{
3 O IFRJ é formado atualmente por 15 campi, a saber: Arraial do Cabo, Belford Roxo, Duque de Caxias, Engenheiro Paulo de Frontin, Mesquita, Nilópolis, Niterói, Paracambi, Pinheiral, Realengo, Resende, Rio de Janeiro, São Gonçalo, São João de Meriti e Volta Redonda, além da Reitoria, instalada no município do Rio de Janeiro.
} 
De acordo com Miles e Huberman (1994), as entrevistas permitem um intenso contato com o campo, proporcionando uma visão aprofundada do fenômeno em observação. Sobre as entrevistas realizadas para este trabalho, identificou-se uma similaridade nos discursos e, portanto, que não seriam necessárias novas entrevistas. A técnica da observação direta participante permitiu a inserção e o envolvimento da pesquisadora no campo, a qual, sendo coordenadora da CGcom - IFRJ, teve acesso aos dados produzidos pelas redes sociais do Instituto gerenciadas por esse setor ${ }^{4}$, além da possibilidade de visualizar as demais páginas administradas por outros setores da Reitoria e dos campi. A partir desse contexto, a observação focou-se em acessos virtuais aos perfis institucionais nas RSDs, identificando-se as plataformas adotadas pelos campi do IFRJ.

Para analisar os dados coletados, utilizou-se a técnica da análise de conteúdo, que, segundo Gil (2002, p.89), “[...] possibilita a descrição do conteúdo manifesto e latente das comunicações.".

A análise de conteúdo pode ser utilizada nos mais variados discursos a fim de buscar compreender a estrutura e a característica da mensagem. Bardin (2011, p. 47) define a análise de conteúdo como

Um conjunto de técnicas de análise das comunicações visando obter, por
procedimentos sistemáticos e objetivos de descrição do conteúdo das mensagens,
indicadores (quantitativos ou não) que permitam a inferência de conhecimentos
relativos às condições de produção/recepção (variáveis inferidas) destas
mensagens.

A análise de conteúdo proposta por Bardin (2011) está definida em três fases: (i) préanálise; (ii) exploração do material; e (iii) tratamento dos resultados. Conforme sugestão de Creswell (2014), as informações foram registradas e armazenadas em forma de notas de campo, transcritas e arquivadas no computador. Os dados coletados foram confrontados com a fundamentação teórica.

Portanto, dada a condição de a pesquisadora ser parte integrante da organização estudada, atuando diretamente sobre o fenômeno em que se pretende intervir, tal circunstância pode ser entendida como facilitadora do rigor metodológico da pesquisa.

\section{A COMUNICAÇÃO PÚBLICA}

Uma vez que o estudo em voga busca investigar a utilização das RSDs no âmbito de uma instituição de educação pública, torna-se importante apresentar, ainda que brevemente, os conceitos que vêm sendo associados à CP.

Comunicar está associado a uma relação social em que uma informação é transformada e transmitida. A CP carrega o mesmo conceito, porém com a diferença de que está voltada ao cidadão para comunicar os serviços do Estado (HASWANI, 2013). O conceito de CP é recente - no Brasil, ainda se encontra em fase de desenvolvimento -, mas tem crescido nos últimos anos (GALINDO; PEREIRA, 2017). Nesse sentido, Suárez e Zuñeda (1999) afirmam que

\footnotetext{
${ }^{4}$ Preliminarmente à realização das entrevistas, a pesquisadora se debruçou sobre a utilização das RSDs oficiais do IFRJ, geridas pela CGcom, a fim de identificar um cenário inicial que demonstrasse, entre os anos de 2014 e 2018, como se usavam as plataformas naquele momento. Para essa etapa da pesquisa, conforme sugere Creswell (2014), os dados foram interpretados diretamente para uma descrição estrutural de como o fenômeno foi experimentado.
} 
Las comunicaciones se han convertido en un patrimonio común de la sociedad, que otorga derechos pero que exige también una serie de obligaciones que las instituciones deben aceptar y cumplir de manera responsable. Dentro de este concepto de comunicación, en su sentido más amplio y en su carácter plural, comenzaremos a hablar, a partir de aquí, de las "Comunicaciones Públicas". (SUÁREZ; ZUÑEDA, 1999, p. 13).

Segundo Zémor (1995) e Haswani (2013), a CP tem como emissor da informação as organizações públicas - com o objetivo de transmitir ao público em geral uma mensagem que não tenha caráter econômico (venda de produtos) - e pode ser classificada em comunicação interpessoal, intrapessoal e em grupo.

Conforme afirma Braga (2004), a Comunicação é admitida como área transdisciplinar do conhecimento, ocupando centralidade e relacionando-se com diversas áreas das Ciências Humanas e Sociais. Dessa mesma forma, destaca-se a abrangência da $\mathrm{CP}$, bem como suas interfaces com as áreas da Administração Pública, bem como com a gestão e a estratégia. Por meio das ações de jornalismo e publicidade institucional, cumpre a missão de informar e aproximar as instituições públicas da sociedade, estreitando o relacionamento com os steakholders e consolidando a imagem e a identidade institucional (BARROS; BERNARDES, 2009; GALINDO; PEREIRA, 2017).

$\mathrm{CP}$, então, deve ser compreendida com sentido mais amplo do que dar informação. Deve incluir a possibilidade de o cidadão ter pleno conhecimento da informação que lhe diz respeito, inclusive aquela que não busca por não saber que existe, à possibilidade de expressar suas posições com a certeza de que será ouvido com interesse e a perspectiva de participar ativamente, de obter orientação, educação e diálogo. (DUARTE, 2012, p.64).

Conforme Brandão (2006), a CP deve também buscar resgatar o sentido social da comunicação. Desse modo, ressalta o surgimento das assessorias de comunicação dos órgãos governamentais, que passaram a influenciar a difusão da CP como informação para cidadania. No setor público, "A comunicação é hoje um ator político dominante, ela é parte integrante da formação do novo espaço público." (LACERDA; GUAZINA, 2012, p.4). Nesse sentido, Brandão (2012) e Haswani (2013) elucidam a importância de se conhecer o público a quem a mensagem se destina, para que seja construído um diálogo, pois, ao se identificar a pessoa com quem se fala, é possível direcionar a comunicação e utilizar a linguagem adequada. Nesse contexto, as TICs estão contribuindo para aproximar o cidadão das informações políticas e das discussões de assuntos de utilidade pública, especialmente a internet, que modificou a forma de fazer comunicação. Assim, a CP pode estar representada, concomitantemente, por redes físicas e digitais (MATOS, 2012).

Como exemplo de um caso de CP e sua utilização associada às RSDs, recorre-se à pesquisa de Rothber e Valença (2014), que, através do caso do governo do Estado de São Paulo, investigaram como "O avanço da exploração das redes sociais por governos pode gerar iniciativas de comunicação pública capazes de contribuir para o aprofundamento da cidadania, pensada como exercício do direito à informação sobre gestão pública.". Os resultados da pesquisa mencionada indicam que as instâncias analisadas utilizam as RSDs preferencialmente como ferramenta estratégica de difusão da informação. Os dados demonstram que muitos governos investem em seus perfis nas RSDs como forma de compor um índice unificado para conduzir o acesso a informações disponíveis em textos noticiosos 
sobre acontecimentos recentes, relacionados à diversidade de políticas públicas executadas nas várias áreas de gestão pública (ROTHBER; VALENÇA, 2014).

Nesses casos, as postagens nas RSDs funcionam como um título que atrai a leitura para uma abordagem mais ampla sobre determinada ação sistemática de governo. Em um curto período, são postadas dezenas de links para textos produzidos pelas assessorias de comunicação pública a fim de divulgar fatos pertinentes à execução de políticas públicas, geralmente aqueles que resultam em benefícios imediatos aos cidadãos, como serviços públicos nas áreas de Assistência Social, Saúde, Educação e Meio Ambiente. De maneira geral, as RSDs institucionais são como portas de acesso à informação antes dispersa por amplos portais eletrônicos do Governo (ROTHBER; VALENÇA, 2014).

Portanto, conforme o exemplo exposto, a CP pode ser utilizada para fortalecer a relação entre governo e sociedade e, com o aporte das plataformas de redes sociais, difundir e coletar informações que contribuam para a tomada de decisão dos gestores do poder público, bem como identificar demandas e possíveis crises. Assim, é importante enfatizar que a CP deve preconizar, além da difusão da informação, a interatividade, permitindo que o cidadão também seja ouvido. Nesse sentido, vale expressar novamente o entendimento de que a CP deve servir de suporte para a utilização das RSDs no âmbito da gestão pública, ao proporcionar ao cidadão tanto a oportunidade de expressar suas posições com a certeza de que será ouvido com interesse quanto a perspectiva de participar ativamente, de obter orientação, educação e diálogo.

\section{A DIFUSÃO DAS RSDs NO ÂMBITO ORGANIZACIONAL}

Com o avanço das TICs, cada vez mais as organizações estão aprofundando-se em novos meios de transmitir informação e integrando-se cada vez mais com seu público. Segundo Corrêa et al. (2015), a internet recebeu uma nova configuração a partir do século $\mathrm{XXI}$, principalmente com o surgimento das empresas pontocom. Posteriormente, criou-se o termo Web 2.0 como um modelo de internet baseado em interatividade e colaboração.

O advento da internet proporcionou uma nova forma como as pessoas se comunicam, uma vez que se fundiu o papel do emissor e do receptor. Os usuários passaram a ser, ao mesmo tempo, produtores e receptores de conteúdo e informação. Neste contexto, destaca-se o surgimento das mídias sociais digitais - textos, imagens, áudio e vídeo em blogs, quadro de mensagens, podcasts, wikis, blogs e afins, que permitem a interação entre os usuários (TERRA, 2009).

Apesar de as mídias sociais e as redes sociais estarem relacionadas, os respectivos conceitos são diferentes. As RSDs são "[...] serviço oferecido por websites que permitem a criação de perfis e a interação entre estes [...]", enquanto as mídias sociais podem ser definidas como "[...] a maneira com que as organizações classificam as redes sociais, como um canal alternativo de comunicação." (ROCHA et al., 2011, p. 2).

Os sites de redes sociais estão inseridos como exemplos de mídias sociais (KAPLAN; HAENLEIN, 2009). Essas plataformas permitem criar perfil com dados pessoais, fotos e vídeos, conectar-se com outras pessoas e organizações, além de trocar mensagens instantâneas. Sendo assim, o rádio, a TV, o jornal, a revista e a Internet são exemplos de mídia; já o Facebook, o Twitter e o Instagram, entre outros, são exemplos de plataformas de Comunicação Digital (ROMANO et al., 2014).

Sobre a evolução das RSDs, Castells (2003, p. 110) considera que "Cada vez mais, as pessoas estão organizadas não simplesmente em redes sociais, mas em redes sociais 
mediadas por computador.". Complementando esse entendimento, Dalcol et al. (2014, p. 158) sinalizam que essas são "[...] uma das formas de comunicação que mais cresce e difunde-se globalmente, modificando comportamentos e relacionamentos.".

Pode-se considerar o crescimento das RSDs como um grande fenômeno cibernético. Em 2017 já havia mais de 122 milhões de usuários de redes sociais, sendo o Brasil o país que mais as utiliza na América Latina (SANTANA; SOUZA, 2017), o segundo país no mundo que mais acessa o Facebook e o primeiro lugar no Twitter (EHRENBERG, 2015). Em consonância com esses dados, confirma-se também o porquê de cada vez mais instituições públicas e privadas inserirem as RSDs nas suas formas de fazer comunicação (ROSA; CASAGRANDA; SPINELLI, 2017; SANTANA; SOUZA, 2017).

Ademais, as RSDs permitem o compartilhamento de informações, valores e objetivos comuns, flexibilizando e agilizando a comunicação interorganizacional. A diferença entre esse tipo de rede e as redes off-line é que as virtuais possibilitam estreitar laços e buscar informações fora da rede da instituição (DALCOL et al., 2014; SILVA; LUFT; OLAVE, 2015). Assim, cada vez mais as organizações reconhecem que as RSDs são uma forma de comunicação direta, barata e eficiente para se relacionar com seus públicos. Nesse meio, o processo comunicacional é multidirecional, feito de "muitos-para-muitos" (LUCAS JÚNIOR; SOUZA, 2011, p. 46). Conforme salienta Silva (2014), se não houver relação entre os seus atores, as redes deixam de existir.

O universo digital tem características próprias, que precisam ser consideradas e exploradas. São elas: interatividade, convergência de meios e o rápido fluxo de informações. Dos três pontos apresentados, a interação é o principal e deve acontecer sempre de forma rápida (EHRENBERG, 2015). Interatividade nas RSDs refere-se ao compartilhamento de conteúdo que deve estar em primeiro plano, mas, paralelamente a isso, deve ocorrer a reprodução de ideias, valores e comportamentos por pessoas que têm alguma relação entre si.

Para que haja envolvimento nas RSDs, é preciso trabalhar com regularidade, atualidade, participação e reciprocidade (CORRÊA, 2010). Para este autor, novos indicadores de sucesso emergem, como: avaliação e perfil do público que acessa a página; possível constituição de comunidade de prática; aspectos de geolocalização, que indicam a localização espacial dos visitantes nas páginas corporativas; formatos e tipos de conteúdo mais atraentes; horários de acesso de maior impacto; níveis de engajamento do público, entre outros (TELLES, 2010; ROSA; CASAGRANDA; SPINELLI, 2017).

Portanto, as RSDs constituem-se como um desafio para quem trabalha com comunicação, pelo fato de terem uma dinâmica muito diferente dos espaços tradicionais como rádio, jornal e televisão. Desse modo, conforme Secom (2014) e Cirucci (2018), gerenciar plataformas de redes sociais é mais que publicar textos, gráficos, imagens e vídeos; é lidar com o comportamento das pessoas, que devem participar ativamente da história nas redes a partir de ações como comentar e compartilhar o conteúdo.

As organizações (sejam públicas, sejam privadas) engajadas nas RSDs percebem melhor a imagem dos steakholders e como devem se relacionar com eles; por isso, a necessidade de estabelecerem o foco no diálogo. Sendo assim, precisam elaborar um plano de comunicação institucional no qual constem as estratégias adequadas para cada público e os objetivos esperados (ROSA; RUSSEL, 2011).

O gerenciamento das RSDs como ferramenta estratégica tem sido cada vez mais comum na Administração Pública. O Facebook e o Twitter são as plataformas de RSDs mais 
utilizadas, ambas com grande aceitação do público brasileiro ${ }^{5}$. A comunicação baseada em RSDs possibilita uma interação entre a organização e o público, constituindo um avanço em prol da democracia (TENÓRIO; DEBOÇÃ, 2016).

Assim, as redes sociais criaram novas possibilidades para a Administração Pública, destacando-se, entre elas, a maior visibilidade das ações, a realização de projetos, a atuação dos gestores e a possibilidade de receber feedback do público. Dessa maneira, ao se optar pelo uso das RSDs, é importante que a pessoa responsável considere os conceitos norteadores incluídos a interatividade, produção de conteúdos e monitoramento dos dados. $\mathrm{Na}$ Administração Pública, as aplicações de tais conceitos devem se apresentar em consonância com valores inerentes à $C P$, sobretudo a informação e a valorização institucional.

Nesse sentido, as RSDs devem ser utilizadas como uma possibilidade que requer rapidez na comunicação, diálogo e interação direta. Para a construção de um ambiente digital com essas características, é preciso saber ouvir, analisar os comentários dos usuários, expressar-se, manter um diálogo com o público, motivar, proporcionar o engajamento com conteúdo atrativo, apoiar e oferecer suporte ao público quando necessário (BERGAMO; TEIXEIRA; SILVA, 2017).

Bueno (2014) ressalta sobre a importância de que a utilização das RSDs no âmbito da Administração Pública esteja atrelada a uma política específica, integrada à Política de Comunicação como um todo, que não apenas defina as diretrizes a serem observadas pelas organizações nesses espaços virtuais, mas que explicite normas e posturas a serem observadas por todos que as integram. Isso significa que uma política de comunicação para RSDs deve incluir um código de conduta para os servidores e funcionários dos vários escalões dentro da instituição, de modo a evitar que ocorram deslizes no uso desses ambientes e no acesso a eles.

\section{RESULTADOS E DISCUSSÃO}

\subsection{Identificação do cenário inicial}

A princípio, serão apresentados os resultados que evidenciam o cenário inicial encontrado correspondente à utilização das RSDs como possível ferramenta estratégica de comunicação no IFRJ, especificamente as plataformas oficiais geridas pela CGcom.

Como unidades de análise desta parte da pesquisa foram consideradas as duas principais páginas em RSD do IFRJ, uma no Facebook e outra no YouTube, ambas gerenciadas pela CGcom, tendo como recorte temporal o período de 2014 (quando o IFRJ iniciou suas atividades nessas plataformas) a 2018.

Os múltiplos dados foram coletados a partir das ferramentas disponíveis nas próprias RSDs para capturar os dados do Facebook e YouTube do IFRJ e compreender seu grau de efetividade. A fanpage do IFRJ no Facebook, com aproximadamente 28 mil curtidas, não se destaca em número de seguidores se comparada com outros Institutos Federais e instituições que compõem a Rede Federal de Educação Profissional e Tecnológica, ficando

\footnotetext{
${ }^{5}$ Segundo Silva, Ribeiro e Silva Filho (2018), em matérias divulgadas no ano de 2018 pelos sites da Revista Exame, Portal G1, Canaltec, Optclean Tecnologia e Techtudo, é perceptível, através de pesquisas e números em grau muito elevado, que, no Brasil, as redes sociais mais utilizadas são Facebook, Twitter e Instagram os quais servem para que os usuários possam se expressar e realizar diversos tipos de atividades utilizando as ferramentas disponibilizadas por estas redes sociais tanto para empreendimento, quanto para disseminação de informações.
} 
apenas em 22ㅇ lugar no ranking elaborado em 2018, com a presença de 40 institutos ${ }^{6}$, conforme Tabela 1.

TABELA 1 - Número de curtidas no Facebook de Instituições que compõem a Rede Federal de

\begin{tabular}{|c|c|c|}
\hline \multicolumn{3}{|c|}{ Educação Tecnológica } \\
\hline Ranking & Instituição & № de Curtidas \\
\hline 1 & IFES & 134.536 \\
\hline 2 & IFSC & 116.985 \\
\hline 3 & IFRN & 109.658 \\
\hline 4 & IFBA & 65.346 \\
\hline 5 & Colégio Pedro I & 66.945 \\
\hline 6 & IFPE & 61.425 \\
\hline 7 & IFCE & 55.020 \\
\hline 8 & IFMG & 54.924 \\
\hline 9 & IFPI & 53.322 \\
\hline 10 & IFRS & 50.274 \\
\hline 11 & IFSP & 49.064 \\
\hline 12 & IFSuldeMinas & 46.199 \\
\hline 13 & IFPR & 44.792 \\
\hline 14 & IFAM & 38.873 \\
\hline 15 & IFGoiano & 37.777 \\
\hline 16 & CEFET - MG & 37.032 \\
\hline 17 & IFC & 36.505 \\
\hline 18 & IFSertãoPE & 34.918 \\
\hline 19 & IFG & 32.486 \\
\hline 20 & IF Baiano & 31.856 \\
\hline 21 & CEFET - RJ & 30.953 \\
\hline 22 & IFRJ & 27.957 \\
\hline 23 & IFS & 27.283 \\
\hline 24 & IFPB & 27.029 \\
\hline 25 & IFRO & 26.961 \\
\hline 26 & IFNMG & 25.084 \\
\hline 27 & IFSul & 24.644 \\
\hline 28 & IFF & 24.405 \\
\hline 29 & IF Sudeste MG & 23.732 \\
\hline 30 & IFPA & 23.083 \\
\hline 31 & IFMT & 22.567 \\
\hline 32 & IFFarroupilha & 21.398 \\
\hline 33 & IFMS & 20.016 \\
\hline 34 & IFTO & 20.002 \\
\hline 35 & IFAL & 19.859 \\
\hline 36 & IFAC & 16.416 \\
\hline 37 & IFAP & 14.321 \\
\hline 38 & IFMA & 12.742 \\
\hline 39 & IFTM & 7.822 \\
\hline 40 & IFRR & 5.079 \\
\hline
\end{tabular}

Fonte: Elaboração própria (2018).

No contexto em que a pesquisa foi realizada, o Facebook era a plataforma de rede social mais usada pelos Institutos Federais, seguido do YouTube. No IFRJ não é diferente,

${ }^{6}$ Esse dado se refere ao período em que a pesquisa foi desenvolvida, obtido por meio de levantamento realizado pelas próprias autoras do trabalho. 
uma vez que o Facebook se posiciona como a RSD que tem recebido mais atenção por parte da comunicação institucional, sendo utilizada por todos os campi e pela Reitoria, consolidando-se como a principal plataforma de interação.

Em relação à convergência de meios, a página oficial do Facebook, gerida pela CGcom, apresentou uma dinâmica entre as publicações ao usar links do site do IFRJ, textos específicos para rede social, imagens, vídeos do YouTube, além de publicação de periódicos e podcasts, sendo que, dos quatro formatos utilizados, as imagens obtiveram maior alcance, interação e reação.

Sobre o fluxo de informações, a página apresentou adequação de linguagem e conteúdo de acordo com a mensagem a ser passada para os steakholders. Observou-se uma linguagem mais coloquial nas postagens destinadas aos alunos e potenciais alunos e um formato mais formal ao descrever temas como ações ligadas a eventos institucionais e ações da gestão. O fluxo de informações aconteceu ao se observar o engajamento e histórias criadas sobre a página. Os dados indicam que o engajamento do público - a soma das pessoas que gostam, comentam, compartilham ou clicam em algum post - foi maior quando postado um conteúdo sobre processo seletivo.

Como ponto de crescimento, conteúdos em imagem e links conseguiram um resultado melhor que as publicações usando somente texto. Ao se manter essa abordagem, a tendência é que mais pessoas passem a visualizar a página. Tendo em vista que postagens com imagens continuavam aparecendo com maior aceitação, a produção de conteúdo foi adaptada para esse formato. Como resultado, posts com apelo visual maior apareceram nos quatro primeiros lugares das publicações com mais destaque.

Sobre o perfil de quem acessou a página, com base nos dados gerados pelos Facebook Insights, o público foi composto prioritariamente por fãs do sexo feminino entre 18 e 34 anos. O público masculino, minoria, também esteve concentrado na mesma faixa de idade do feminino.

Em relação à localização dos visitantes, com maior visualização dos posts do IFRJ é o município do Rio de Janeiro, seguido de algumas cidades, como Volta Redonda e Duque de Caxias, locais onde o Instituto tem alguns dos seus campi instalados. A presença de visitantes de São Paulo e Curitiba na lista de cidades com maior alcance das publicações suspeita-se em razão da realização de concursos públicos que ocorreram durante o período analisado.

Acerca dos conteúdos mais atraentes, o processo seletivo foi a temática que conquistou maior número de interações e alcance, seguido do anúncio de concurso público para docentes e técnicos administrativos.

Quanto ao YouTube, Ehrenberg (2015) defende que essa rede social se destina à publicação de vídeos, sendo uma alternativa para divulgação de conteúdos institucionais e publicidade de serviços. Além disso, permite que os usuários compartilhem em outras plataformas digitais o conteúdo ali publicado, aumentando assim a visibilidade dele.

Tal como no Facebook, o público que acompanha a página oficial do YouTube do IFRJ, gerido pela CGcom, é predominantemente jovem. Vídeos relacionados à política institucional ou aos gestores têm um alcance menor. Os conteúdos mais visualizados são os vídeos referentes a processos seletivos para cursos técnicos e os vídeos que apresentam os cursos da Instituição e imagens relacionadas à tecnologia (como os temas de Robótica e Jogos Digitais).

Sobre os dados relacionados à produção de vídeos para o YouTube, entre o período abarcado na pesquisa, observou-se uma grande oscilação: em 2014, foram sete vídeos pro- 
duzidos; em 2015, um total de 41 vídeos; em 2016, foram 16 vídeos; oito em 2017; e 22 em 2018.

Corrêa (2010) destaca que as redes sociais precisam de regularidade e atualidade, pontos que foram retomados na produção de 2018, com 14 vídeos a mais que em 2017. Porém, a autora aponta que é necessário haver reciprocidade, o que não aconteceu em nenhum dos vídeos publicados pelo IFRJ, em razão do bloqueio da área de comentários pelos gerenciadores da página. A conta do Instagram não foi analisada para essa pesquisa, pois foi lançada apenas em janeiro de 2019.

\title{
5.2 Análise por categorias da utilização das RSDs no IFRJ
}

\subsubsection{Categoria 1: Interatividade}

Na Administração Pública, ao adicionar RSDs em seu modelo de comunicação, a organização está abrindo novas portas, privilegiando a transparência e a interatividade entre a instituição e o seu público. É visto como um reconhecimento de que o poder público utiliza esses meios para buscar ampliar o diálogo e sua aproximação com o cidadão (BRASIL, 2014). Conforme dito, as RSDs do IFRJ - Facebook, Youtube, Instagram - são gerenciadas pela CGcom da Reitoria; já as dos campi, pelas assessorias de comunicação locais.

No que tange às RSDs do IFRJ gerenciadas pela CGcom, no período de 2014 a 2018, os resultados indicam que a interatividade não foi explorada e que a comunicação nessas redes teve apenas uma via: a de transmissão de mensagens. Na página do Facebook, por exemplo, não houve resposta alguma da Instituição referente a qualquer comentário recebido - independentemente de ter sido uma dúvida, um elogio, uma sugestão ou crítica.

Já no YouTube, o espaço "comentários" estava bloqueado a quem acessasse os vídeos, o que reforça a falta de interação entre o Instituto e o público entre 2014 e 2018 . Essa escassez de diálogo com o internauta foi uma característica comum em ambas as RSDs do IFRJ analisadas, como se pode observar na transcrição das entrevistas a seguir:

Nunca respondi. Eu respondi uma semana quando você me solicitou para ver como ia ser, e deu certo, e as pessoas me respondiam e curtiam. Não fui orientada a isso. Nunca teve essa raiz do Facebook, da rede social, que seria o certo. De repente, a gente olha e decide se pode postar lá ou não. Não era levado a sério, vamos dizer, a rede social. Era sempre uma coisa "se der, joga lá". Não era pensado para rede social (ENTREVISTADO 1).

\begin{abstract}
Na gestão anterior, a gente tinha uma política de simplesmente não responder aos comentários nas redes sociais. Política essa que vinha de cima, da chefia. Eu particularmente não concordo, mas eu respeitava e fazia o que era solicitado. Agora, com a mudança de gestão, a gente tem esse interesse em começar a responder mais. A gente teve uma experiência de começar a responder esses comentários, e foi bacana. A estagiária começou a responder, foi interessante essa experiência, e a gente quer retornar com isso, na medida do possível, novamente, porque nem todos os comentários a gente vai conseguir responder devido à quantidade de pessoas que a gente tem trabalhando com isso (ENTREVISTADO 2).
\end{abstract}

Esse cenário contrasta com o entendimento de Ehrenberg (2015), de que é importante explorar a interatividade e o rápido fluxo de informações promovido pelas RSDs. Além disso, diverge do conceito básico da Comunicação Pública: o de que a informação deve ser tratada como prioridade, sendo essencial o diálogo entre a organização e o cidadão. 
Responder o público passa, então, a ser um critério importante para a construção de uma relação, sobretudo nos momentos em que o cidadão busca esclarecimentos sobre programas e ações institucionais, pois o primeiro princípio da utilização das RSD's no âmbito da $\mathrm{CP}$ é o de que a comunicação deve ser pautada principalmente pela troca de informações. Essa troca é a essência desse novo meio de comunicação e pressupõe um retorno mútuo (BRASIL, 2018).

Todavia, diferentemente do observado em relação às plataformas gerenciadas pela CGcom, com base nas entrevistas e na observação direta dos perfis dos campi do IFRJ, identificou-se uma maior interação do Instituto com os usuários, diante de respostas de dúvidas e comentários.

A primeira regra que o diretor me colocou foi: "A gente não deixa ninguém sem resposta. A gente responde todo mundo!". Às vezes, em época de processo seletivo, eu gasto o dia todo só no Facebook. Nosso WhatsApp não deu certo por causa disso. Eu ficava o dia todo respondendo mensagem do WhatsApp, mas, de comentários, a gente responde a todos e, de vez enquanto, a gente dá uma interagida, que foi uma coisa que eu peguei da Prefeitura de Niterói. Alguém marca uma pessoa, e eu coloco: "Ah, marca mesmo", como se tivesse conversando com a pessoa. O pessoal gosta (ENTREVISTADO 4).

Eu respondo caso seja alguma dúvida a respeito, por exemplo: qual é o horário das aulas, telefone da secretaria, tanto nos comentários como também no chat (ENTREVISTADO 3).

Eu me lembro sobre a gente ter falado sobre isso em alguma reunião da Ascom ${ }^{7}$, dessa interação na rede social, da importância. Então eu acabo sempre respondendo porque eu estou em contato direto com a página do Facebook todos os dias. Todos os dias eu entro e trabalho ali, eu utilizo, estou sempre atualizando, estou sempre vendo o que está acontecendo, compartilhando. Eu utilizo bastante e fico conectada o dia todo (ENTREVISTADO 6).

Foi um pedido também da direção que houvesse essa interação, principalmente no inbox do Facebook, que recebe muitas perguntas, que é a caixa de mensagens. Eu sempre separo o meu primeiro momento. Quando eu chego no campus, a primeira coisa que eu faço é responder as mensagens inbox, mas também têm as interações nos posts do Facebook e no Instagram, que eu costumo deixar para fazer quando eu volto do almoço. A taxa de resposta antes do recesso estava entre $92 \%$ e $93 \%$, não me recordo direito. Agora está $53 \%$, e eu acredito que o Facebook ainda vai atualizar. Como ficou em recesso, as mensagens demoraram para ser respondidas, mas antes estava $92 \%$ ou $93 \%$, e eu espero nesses próximos dias voltar a essa taxa de resposta (ENTREVISTADO 5).

Os relatos apresentados corroboram o entendimento de que a falta de resposta das instituições públicas para os cidadãos pode gerar uma má interpretação por parte deles. Portanto, a interatividade é um recurso indispensável para que se alcancem os resultados esperados pela comunicação que acontece no ambiente de mídias sociais (BRASIL, 2014). Ademais, é importante compreender que as RSDs permitem uma avaliação de baixo custo das opiniões dos públicos, colaborando para a elaboração de novos projetos e políticas em instituições públicas. Logo, o gerenciamento está diretamente relacionado à estratégia (SANTANA; SOUZA, 2017), que também direciona a produção de conteúdo e influência na definição dos métodos de monitoramento dos dados.

\footnotetext{
${ }^{7}$ No período de recorte desta pesquisa, a CGCom era Assessoria de Comunicação (Ascom).
} 


\subsubsection{Categoria 2: Conteúdo}

A partir do monitoramento das mídias sociais dos próprios canais oficiais - inclusive dos tipos e volumes de interações -, foi possível extrair os temas que obtiveram os melhores resultados positivos e merecem atenção. É preciso analisar para entender quais elementos tornaram a informação positiva e despertaram o interesse do cidadão para, então, ampliar o volume, a frequência e os estilos de divulgação do conteúdo nos canais oficiais. De acordo com o que propõe Juliani et al. (2012), por meio das RSDs, espera-se gerar, especialmente no caso do IFRJ, uma autopromoção da Instituição de Ensino, à medida que as atividades são publicadas e o conteúdo é compartilhado.

Com os resultados da pesquisa, identificou-se que, sempre que a temática do processo seletivo era abordada - como post, vídeo ou publicação -, o alcance era elevado e mais pessoas interagiam com as redes do IFRJ, comentando ou compartilhando o conteúdo publicado. Esse foi um ponto positivo, pois trabalhar esse contexto permite alcance e engajamento maiores, conforme sugerem os seguintes trechos das entrevistas:

Processo seletivo e cursos de extensão geram muito engajamento, as pessoas curtem, comentam marcando outras pessoas e também compartilham (ENTREVISTADO 5).

Eu sinto que as publicações normalmente que geram mais interação são as publicações realmente dos processos seletivos, dos cursos técnicos, seja concomitante/subsequente, do integrado, a gente costuma ter bastante interatividade nesses posts, principalmente de dúvidas (ENTREVISTADO 2).

Após mapear os temas que geraram maior engajamento, é importante destacar a relevância do planejamento, a fim de que, com o uso das mídias sociais, a Instituição possa alcançar seus objetivos e sua missão. Para isso, a partir do levantamento de todo o universo de conteúdos do Instituto, da identificação dos assuntos estratégicos e da distribuição das informações, o responsável pela gestão das redes sociais poderá avançar para tratar dos temas prioritários, em formatos disponíveis e desejáveis para falar com os públicos de interesse, e também com o tipo de conteúdo adequado a cada perfil de usuários (BRASIL, 2014).

Além de definir o conteúdo, é importante que o profissional responsável por o criar para a web preocupe-se sempre em facilitar esse acesso à informação com uma linguagem clara e de fácil interpretação por parte dos usuários (PIMENTA et al., 2002; ROCHA; DUARTE, 2012). Essa preocupação com a acessibilidade ficou notória nos seguintes trechos das entrevistas:

Quanto à acessibilidade, meu pensamento é deixá-lo bem claro para que diferentes tipos de pessoas com diferentes níveis de escolaridade possam entender. Quanto às questões de deficientes visuais, não há, ainda, esse pensamento na hora de elaborar os posts. Eu fico realmente pensando o que eu posso fazer e acabo não tendo muito conhecimento de técnicas, de algo prático para ser feito além dessa hashtag "Pra cego ver", que eu já vi em outras redes sociais. Então, acredito que principalmente o tema acessibilidade está muito em alta, está em alta porque é muito necessário, deveria estar sempre, e eu acho que é um assunto que a gente podia pensar mais e elaborar mais, sim, porque, até então, pelo menos no meu campus, não vem sendo elaborado. O que eu penso quanto à acessibilidade dos posts é ver se eles estão claros, para não ficar um termo muito técnico. Às vezes pode ter uma dificuldade ou outra minha de pensar nisso (ENTREVISTADO 5). 
Eu tenho a preocupação de deixar todas as postagens, todas as publicações, abertas para serem compartilhadas, inclusive por pessoas que não seguem a página. Eu me preocupo que a informação seja transmitida além de mim, que seja passada adiante. A integração acadêmica, principalmente, ela tem que acontecer, é essencial. E, dentro do campus, dentro do IFRJ, principalmente pela existência do Napne, a gente tem pessoas com deficiência, a gente tem pessoas que precisam ter o material disponibilizado, que precisam que aquilo seja acessível para eles. E 2019 está aí, é um ano novo. Pretendo trabalhar a melhora de muitas coisas, e uma delas é a acessibilidade (ENTREVISTADO 6).

Segundo Torres e Mazzoni (2004) e Souza e Tabosa (2014), criar um conteúdo acessível para as RSDs não significa retirar sons nem animações, mas garantir que essas informações sejam transmitidas, mesmo com a ausência desses recursos.

No âmbito do IFRJ, nenhum documento norteador elaborado pelo Governo Federal foi encontrado. Além disso, alguns entrevistados relataram não saber como associar o conceito de acessibilidade aos perfis institucionais:

Eu não tenho ideia de como a gente pode fazer isso. Inclusive eu aprendi isso aqui, porque, na faculdade, eu tive grade de Redes Sociais, e isso não foi uma pauta. Eu aprendi aqui, quando a gente foi fazer um e-mail, que eu esqueci de colocar a \#acessibilidadeparatodos e vi que era óbvio que isso tinha que ter. Aí que me deu o clique na cabeça, e fui lá futucar no site e vi, na parte de cima, "Acessibilidade". Aqui que eu fui me preocupar com essa questão, mas, na rede social, não tenho nem ideia do que fazer. Até pelo discurso da nossa instituição, de ser uma instituição inclusiva. Não adianta a gente falar e, na prática, não fazer (ENTREVISTADO 1).

Eu sempre observo outras páginas, de como o pessoal está gerenciando, para ter referência. Já observei que isso é uma tendência, já tive desejo de seguir nessa linha. Hoje não faço e não me preocupo por conta de não me sentir preparada, habilitada, e não saber como fazer (ENTREVISTADO 3).

Poder acessar o conteúdo publicado nas RSDs é ter direito ao acesso à informação, uma garantia de interação e participação nesses ambientes. Uma vez que esse meio digital é uma alternativa de conseguir alcance e engajamento com baixo custo, o conteúdo publicado nas RSDs precisa ser o mais acessível possível.

Devido à sensibilização que a gente teve do nosso servidor revisor de Braile, que trabalha na Pró-Reitoria de Extensão, ele é deficiente visual, ele é cego, e devido a algumas contribuições dele, a gente começou a atentar mais para esse quesito e a gente, sempre que utiliza, que publica um conteúdo de imagem, a gente tenta utilizar a hashtag \#acessibilidadeéparatodos ou \#acessibilidadeédireitodetodos, porque, inclusive por uma contribuição dele, inclusive a gente evita o \#pracegover. Como ele bem destacou, cego não vai ver, independente de como você escreva, e ele nos relatou que achava essa hashtag muito desconfortável. Então a gente evita de utilizar ela. Infelizmente a gente ainda não dispõe de um intérprete em Libras para fazer esse conteúdo dos vídeos. Isso é uma coisa que está nos planos do Instituto (ENTREVISTADO 2).

O nosso intérprete de Libras no campus, ele é muito ativo nisso, ele bate muito nessas teclas. A gente faz, inicialmente, mas a nossa proposta é aumentar, a gente faz essa questão dos vídeos de lançamento de edital em Libras, pelo menos. A UFF tem feito do Pra Cego Ver, que eu acho muito legal, de você descrever o texto por causa dos leitores de tela. Eu e a coordenadora de Extensão, a gente já conversou de tentar usar isso, a gente tá sempre marcando, a gente conversa, marca uma 
reunião, e a gente fala: "Vamos começar a usar". O Pra Cego Ver, quando eles começaram a usar, eu achava que o texto ficava muito grande e tal, e pra mim hoje é supernormal. Eu já leio normalmente o Pra Cego Ver antes de ler a publicação, que eu acho interessante ver e até um pouco para absorver como que está sendo essa tradução (ENTREVISTADO 4).

Pensar em acessibilidade nas mídias sociais é pensar no processo de inclusão, uma vez que o conteúdo digital se tornou uma das principais fontes de informação e comunicação, devendo, portanto, ser acessível a todos. Quando organizações produzem conteúdo acessível, como em algumas situações do IFRJ exemplificadas, a comunicação com o público externo e interno se torna muito mais eficiente e alcança um número maior de pessoas. Assim, a acessibilidade evita distorções na mensagem e permite uma compreensão mais ampla do que se está sendo dito. Portanto, conteúdos com acessibilidade nas redes sociais possibilitam ainda uma aproximação com o público, ao indicar que todos são levados em conta pela comunicação institucional, além de ajudar a reforçar e fortalecer uma sociedade mais igualitária ${ }^{8}$.

\subsubsection{Categoria 3: Monitoramento dos Dados}

O monitoramento dos dados nas RSDs é fundamental, é a base para o planejamento geral, pois a partir dele é que se identifica a importância dos temas, descobre a real percepção do cidadão a respeito dos assuntos estratégicos, reconhecem novas oportunidades de atuação, geração e disseminação de conteúdos, além de criar estruturas que suportem as estratégias e processos de comunicação (BRASIL, 2014).

Segundo Thomas et al. (2015),

El monitoreo y análisis de contenidos en redes sociales de internet permite la detección y Descubrimiento de nuevos conocimientos, identificar las opiniones, los comentarios y las evaluaciones de los consumidores y usuarios, realizar un análisis cualitativo y cuantitativo, predecir eventos y tendencias, identificar las quejas y preocupaciones de manera oportu na para evitar las crisis y el descrédito; diseñar nuevas estrategias, orientar la toma de decisiones, así como el desarrollo de innovación de productos y servicios, entre otros.

Bueno (2014) também compreende que avaliar o trabalho desenvolvido nas RSDs é uma atividade primordial. A coleta e análise dos dados deve ser tanto quantitativa quanto qualitativa, buscando, a partir dos resultados, atingir um maior alcance e engajamento (BUENO, 2014).

Em geral, o monitoramento dos dados é uma etapa essencial e que deve ser considerada pelas organizações como orientação no processo de tomada de decisões. No IFRJ, os entendimentos acerca dessa etapa no processo de gerenciamento de RSDs podem ser identificados nos relatos a seguir:

É assim: postou, vai ficar lá. Nós fomos descobrir agora o melhor horário, isso nunca foi pensado antes, pelo menos não na minha rotina. Isso nunca foi conversado. Nunca foi pensado se é melhor colocar um vídeo, um texto ou postar

\footnotetext{
8 Acessibilidade nas Redes Digitais e no Conteúdo Digital. Disponível em: https://talentoincluir.com.br/emprego/acessibilidade-nas-redes-sociais-e-no-conteudo-digital/.
} Acesso em: 15 dez. 2019. 
só uma chamada. Nunca teve essa preocupação... nunca me orientaram a fazer isso. É uma prática que eu trouxe das minhas redes sociais (ENTREVISTADO 1).

\begin{abstract}
Eu estou me costumando com essa análise de resultado agora, porque na verdade quem fazia isso aqui era você. Você que costumava fazer essa parte, olhar as estatísticas. Eu praticamente não entro nessa parte do Facebook; agora que eu estou começando a dar uma olhada, a entender, a pesquisar um pouco mais sobre as estatísticas do Facebook. Eu ainda estou me familiarizando com essa questão de análise de resultado, mas, na medida do possível, eu consigo me virar (ENTREVISTADO 2).
\end{abstract}

A gente não voltava para ver não. A gente simplesmente chegava e postava, e não havia nenhum tipo de gerenciamento sobre isso (ENTREVISTADO 7).

Como pode ser observado nesses relatos, o monitoramento das RSDs no IFRJ era é incipiente e não sistematizado. Com isso, a Instituição, além de ter deixado de identificar a satisfação do seu público em relação aos conteúdos compartilhados, desconsiderava uma das premissas básicas em relação a esse monitoramento: que ele seja contínuo e se baseie em parâmetros de comparação (THOMAZ et al., 2015).

\title{
6 CONSIDERAÇÕES FINAIS
}

É consenso que a comunicação mudou muito nos últimos anos, principalmente depois dos avanços da tecnologia da informação. Assim, acredita-se que acompanhar esse desenvolvimento é um desafio para organizações em geral, mas, principalmente, para as instituições públicas, que devem atuar estrategicamente e em consonância com os Princípios da Administração, sempre considerando o foco no cidadão.

No que tange ao objetivo principal deste estudo - analisar a produção estratégica de conteúdo nas RSDs oficiais do IFRJ entre 2014 e 2018 -, julga-se que os dados coletados na pesquisa possibilitaram um aprofundamento no assunto sobre o uso das RSDs no âmbito público (especialmente em uma instituição de educação), considerando-se os conceitos atrelados à Comunicação Pública.

A pesquisa alcançou seu objetivo, identificando como foi feito o gerenciamento das RSDs no IFRJ durante esse recorte temporal. Os resultados elucidam que, em razão da ausência de uma Política de Utilização de Redes Sociais Digitais e da inexistência de uma Política de Comunicação articulada com o Plano de Desenvolvimento Institucional, as ações concernentes à gestão de RSDs no IFRJ dialogavam tenuamente com os conceitos da $\mathrm{CP}$, limitando-se apenas à transmissão de informação ao seu público-alvo. Os conteúdos produzidos e compartilhados por meio das RSDs analisadas não eram pensados em articulação com as estratégias da Instituição, mas, sim, criados conforme a necessidade do momento, como, por exemplo, ocorria com a divulgação de processos seletivos para alunos e servidores. Com isso, ressalta-se novamente a importância de se estabelecer uma Política de Utilização de Redes Sociais Digitais que normatize os usos das RSDs no âmbito do IFRJ.

Ainda que implicitamente, o uso da RSDs no IFRJ é tido como ferramenta de maximização da imagem institucional, pois, especialmente através do Facebook, tem repercutido positivamente as publicações que visam comunicar as ações institucionais com os seus públicos-alvo. Todavia, apesar de o IFRJ usar as RSDs para comunicar as suas ações institucionais com os seus públicos, a interatividade - importante conceito relacionado à gestão de redes sociais - não era, até então, explorada. 
Notou-se também que o monitoramento dos dados nas RSDs do IFRJ ainda é feito de forma incipiente e sem padronização. Apesar dos resultados poucos satisfatórios a respeito do uso das RSDs com base na aplicação dos conceitos relacionados, a pesquisa, ainda assim, possibilitou verificar a legitimidade do trabalho realizado pela CGcom do IFRJ e identificar essa coordenação como único setor responsável por coordenar as ações gerais de comunicação institucional.

Portanto, considera-se que trabalhar com as RSDs em uma organização pública significa garantir o acesso à informação ao cidadão e a transparência, bem como prezar pela imagem institucional. Dessa forma, o IFRJ precisa priorizar as RSDs e não mais encará-las como segunda opção ou modismo. Diante desses fatos, é possível concluir que as RSDs são a oportunidade de conhecimento e aproximação com o público do IFRJ e que as palavraschave desse meio são interação e diálogo. O Instituto não pode mais falar sozinho; precisa realmente trabalhar em rede, com planejamento e foco no engajamento das pessoas, sabendo ouvir, responder e compreender o que o seu público espera da comunicação em RSDs e da Instituição como um todo. Ademais, é importante ressaltar que este trabalho não pretendeu esgotar os assuntos aqui abordados, principalmente por se tratar de uma área nova e com mudanças constantes.

\section{REFERÊNCIAS}

BARDIN, L. Análise de conteúdo. Lisboa: Edições 70, 2011. 279p.

BARROS, A. T. de; BERNARDES, C. B. Contribuições francesas ao debate brasileiro sobre Comunicação Pública. In: CONGRESSO BRASILEIRO DE CIÊNCIAS DA COMUNICAÇÃO - INTERCOM, 32., 2009, Curitiba. Anais [...]. Curitiba, 2009.

BERGAMO, F.; TEIXEIRA, F. L. C.; SILVA, M. A. M. da. Cibercultura e inovação: reflexões sobre o ambiente inovativo das organizações na era da informação e seus cenários futuros. Brazilian journal of management \& innovation, v. 4, n. 2, jan./abr. 2017.

BRAGA, A. Comunicação e transdisciplinaridade: na trilha de Palo Alto. In: ENCONTRO DA COMPÓS, 13., São Bernardo do Campo. Anais [...]. São Bernardo do Campo: UMESP, 2004.

BRANDÃO, E. P. Conceito de Comunicação Pública. In: DUARTE, J. (org.). Comunicação pública: estado, mercado, sociedade e interesse público. 3. ed. São Paulo: Atlas, 2012.

BRANDÃO, E. P. Usos e significados do conceito Comunicação Pública. In: ENCONTRO DOS NÚCLEOS DE PESQUISA DA INTERCOM, 6., 2006, Brasília, DF. Anais [....] Brasília, DF, 2006.

BRASIL. Manual de orientação para atuação em mídias sociais: identidade padrão de comunicação digital do Poder Executivo Federal. 2014. Disponível em: http://www.secom.gov.br/pdfs-da-area-de-orientacoes-gerais/internet-eredessociais/secommanualredessociaisout2012 pdf.pdf. Acesso em: 13 jul. 2020.

BRASIL. Lei no 11.892, de 29 de dezembro de 2008. Institui a Rede Federal de Educação Profissional, Científica e Tecnológica, cria os Institutos Federais de Educação, Ciência e Tecnologia, e dá outras providências. Disponível em: 
http://www.planalto.gov.br/ccivil 03/ Ato2007-2010/2008/Lei/L11892.htm. Acesso em: jun. 2020.

BRASIL. Lei no 9.394, de 20 de dezembro de 1996. Estabelece as diretrizes e bases da educação nacional. Diário Oficial da União, Brasília, DF, 24 dez. 1996. Disponível em http://portal.mec.gov.br/seed/arquivos/pdf/tvescola/leis/lein9394.pdf. Acesso em: 13 jul. 2020.

BUENO, W. C. Comunicação empresarial: alinhando teoria e prática. Barueri: Manole, 2014.

CAPOBIANCO, L. A. Revolução em curso: internet, sociedade da informação e cibercultura. Universidade de São Paulo. São Paulo, 2010.

CASTELLS, M. A galáxia da internet: reflexões sobre a internet, os negócios e a sociedade. Rio de Janeiro: Jorge Zahar, 2003.

CIRUCCI, A. M. A. New women's work: digital interactions, gender, and social network sites. International journal of Communication, v. 12, 2018.

CORRÊA, M. I. S. Comunicação Digital e novas mídias institucionais. In: KUNSCH, M. M. K. (org.). Comunicação organizacional. São Paulo: Saraiva, 2009. p. 317-335.

CORRÊA, M. I. S. Comunicação Digital e novas mídias institucionais. In: KUNSCH, M. M. K. (org). Comunicação organizacional. Histórico, fundamentos e processos. São Paulo: Saraiva, 2010, p. 317-335.

CORRÊA, M. I. S. et al. As redes sociais digitais na comunicação organizacional: um estudo de caso na cidade do Recife. Revista de gestão organizacional, v. 13, Edição Especial, p. 340348, 2015.

CRESWELL, J. W. Investigação qualitativa e projeto de pesquisa: escolhendo entre cinco abordagens. 3. ed. Porto Alegre: Penso, 2014.

DALCOL, C. et al. Mensuração da competitividade em instituições de ensino superior privadas com base nas redes sociais digitais. Perspectivas em gestão \& conhecimento, João Pessoa, v. 4, n. especial, p. 96-108, out. 2014. Disponível em:

https://periodicos.ufpb.br/index.php/pgc/article/view/19291/11752. Acesso em: 13 jul. 2020.

DELORS, Jacques et al. (Org.). Educação: um tesouro a descobrir: Relatório para a UNESCO da Comissão Internacional sobre Educação para o século XXI. Brasília: UNESCO, 2010.

DUARTE, J. Instrumentos de Comunicação Pública. In: DUARTE, Jorge (org.). Comunicação Pública: estado, mercado, sociedade e interesse público. 3. ed. São Paulo: Atlas, 2012.

DUARTE, M. Y. M. Estudo de caso. In: DUARTE, Jorge; BARROS, Antônio (org.). Métodos e técnicas de pesquisa em Comunicação. 2. ed. São Paulo: Atlas, 2015. 
EHRENBERG, K. C. Nike e Adidas na rede: estratégias de marketing esportivo no ambiente digital. In: BUENO, Wilson da Costa (org.). Estratégia de comunicação nas mídias sociais. São Paulo: Manole, 2015.

EMPRESA BRASILEIRA DE SERVIÇOS HOSPITALARES. EBSERH. Manual de condutas em mídias sociais. 2018. Disponível em:

http://www2.ebserh.gov.br/documents/695105/3801429/MANUAL+DE+CONDUTA+EM+M \%C3\%8DDIAS+SOCIAIS.pdf/a6bf33d3-3236-45a3-b495-7884af7bad2e. Acesso em: 16 fev. 2020.

FARRANHA, A. C. et al. Administração pública e redes sociais (Facebook e Twitter): Analise de casos selecionados. Revista negócios em projeção, v.5, n. 1. Brasília, 2014.

FARRANHA, A. C; SANTOS, V. S. dos. Ativismo em redes sociais digitais: análise da rede cerrado e suas interfaces na promoção de políticas públicas sustentáveis. Revista Direitos Emergentes na Sociedade Global, v.4, n.1, Santa Maria - RS, 2015.

GALINDO, F.; PEREIRA, K. A emergência da Comunicação Pública nas Ciências Sociais: um estudo bibliométrico. Revista Sodebras, v. 12, n. 136, abr. 2017.

GIL, Antonio Carlos. Como elaborar projetos de pesquisa. 4. ed. São Paulo: Atlas, 2002.

HASWANI, M. F. Comunicação Pública: bases e abrangências. São Paulo: Saraiva, 2013.

HENRIQUES, M. S; SANT'ANA, L. F. A construção da proximidade na Comunicação Pública: mídia social e a ruptura da impessoalidade. Organicom, n. 22, 2015.

JULIANI, D. P. et al. Utilização das redes sociais na educação: guia para o uso do Facebook em uma instituição de ensino superior. Novas tecnologias na Educação. v. 10, n. 3, dez. 2012.

KAPLAN, A. M.; HAENLEIN, M. Users of the world, unite! The challenges and opportunities of social media. Business Horizons, v. 53, p. 59-68, 2009.

LACERDA, L. N. de; GUAZINA, L. S. A comunicação interna na Comunicação Pública brasileira: compreendendo o cenário atual. In: CONGRESSO BRASILEIRO DE CIÊNCIAS DA COMUNICAÇÃO - INTERCOM, 35., 2012, Fortaleza. Anais [...]. Fortaleza, 2012.

LUCAS JÚNIOR, D.; SOUZA, C. A. Estabelecendo estratégias de comunicação integrada nas redes sociais: análise de uma instituição financeira brasileira. Revista pensamento \& realidade, v. 26, n. 3, 2011.

MARQUES, A.; DELBARD, D. Comunicação Pública na web: uma reflexão sobre a aplicação dos princípios da Web 2.0 no fazer comunicacional. In: CONGRESSO BRASILEIRO DE CIÊNCIAS DA COMUNICAÇÃO - INTERCOM, 38., 2015, Rio de Janeiro, RJ. Anais [...]. Rio de Janeiro, RJ, 2015. 
MATOS, H. Comunicação Pública, esfera pública e capital social. In: DUARTE, Jorge (org.). Comunicação Pública: estado, mercado, sociedade e interesse público. 3. ed. São Paulo: Atlas, 2012.

MILES, M. B.; HUBERMAN, M. Qualitative data analysis: an expanded sourcebook. 2. ed. California: Sage, 1994.

PEREIRA, D. A.; BORGES, M. K. Mídias sociais como estratégia de comunicação em uma instituição de ensino: perspectivas e desafios. Revista GUAL - Gestão Universitária da América Latina, Florianópolis, v. 5, n. 2, p. 217-327, ago. 2012.

PIMENTA, M. et al. A (in)acessibilidade de sites governamentais. In: SIMPÓSIO SOBRE FATORES HUMANOS EM SISTEMAS COMPUTACIONAIS (IHC), 2002, Fortaleza. Anais [...]. Fortaleza, 2002.

RECUERO, Raquel. Redes sociais na internet. Porto Alegre: Sulina, 2009.

ROCHA, J. A. P.; DUARTE, A. B. S. Diretrizes de acessibilidade web: um estudo comparativo entre as WCAG 2.0 e o e-MAG 3.0. Inclusão Social, Brasília, DF, v. 5, n. 2, p.73-86, jan./jun. 2012.

ROCHA, T. V. et al. O uso das redes sociais na construção do relacionamento com clientes: um estudo de caso múltiplo no Brasil. In: ENCONTRO NACIONAL DA ASSOCIAÇÃO NACIONAL DE PÓS-GRADUAÇÃO E PESQUISA EM ADMINISTRAÇÃO, 35., 2011. Rio de Janeiro. Anais [...] Rio de Janeiro: Anpad, 2011.

ROMANO, F. M. et al. O impacto das mídias sociais digitais na Comunicação Organizacional das empresas. Future studies research journal, v. 6, n. 1, p. 5382, 2014.

ROSA, R. O.; CASAGRANDA, Y. G.; SPINELLI, F. E. A importância do marketing digital utilizando a influência do comportamento do consumidor. Revista de tecnologia aplicada, v. 6, n. 2, p. 28-39, 2017.

ROSA, R.; RUSSEL, R. O desafio das organizações nas redes sociais: um olhar no Ttwitter da Natura, da Vivo e do Submarino. In: CONGRESSO BRASILEIRO CIENTÍFICO DE COMUNICAÇÃO ORGANIZACIONAL E DE RELAÇÕES PÚBLICAS - ABRAPCORP, 5., 2011, São Paulo. Anais [...]. São Paulo, 2011.

ROTHBERG, D; VALENÇA, A. S. Comunicação Pública para a cidadania no avanço das redes sociais oficiais. Revista interamericana de comunicação midiática, v. 13. n. 26, Santa Maria, RS, 2014.

SANTANA, M. B. de; SOUZA, C. G. B. de. Uso das redes sociais por órgãos públicos no Brasil e possibilidades de contribuição do monitoramento para gestão. Revista gestão organizacional, v. 15, n. esp., p. 99-107, 2017. 
SECRETARIA DE COMUNICAÇÃO SOCIAL (SECOM). Manual de orientação para atuação em mídias sociais: identidade padrão de comunicação digital do Poder Executivo Federal, 2014. Disponível em: http://www.secom.gov.br/pdfs-da-area-de-orientacoes-gerais/internet-eredes-sociais/secommanualredessociaisout2012 pdf. Acesso em: 16 fev. 2020.

SILVA, D. M. da; RIBEIRO, A. C. D; SILVA FILHO, E. A. As redes sociais como ferramenta para acesso à informação na Administração Pública. Perspectivas em políticas públicas, Belo Horizonte, v. XI, n. 21, p. 267-294, jan/jun, 2018.

SILVA, A. K. A. da. A dinâmica das redes sociais e as redes de coautoria. Perspectivas em gestão \& conhecimento, João Pessoa, v. 4, n. esp., p. 27-47, out. 2014.

SILVA, W. A.; LUFT, M. C. M. S.; OLAVE, M. E. L. Papel das redes sociais virtuais no relacionamento entre empresas juniores em uma universidade federal. Revista gestão.org, v. 13, n. esp., p. 244-253, 2015.

SOUZA, O. de; TABOSA, H. R. Virando a página: um novo conceito de acessibilidade na web para deficientes visuais. Informação \& sociedade: estudos, João Pessoa, v. 24, n. 1, p. 145161, jan./abr. 2014.

SUÁREZ, A. A.; ZUÑEDA, C. C. Comunicaciones públicas: el modelo de la comunicación integrada. 1. ed. Buenos Aires: Temas Grupo Editorial, 1999. 303p.

TELLES, A. Revolução das mídias sociais: cases, conceitos, dicas e ferramentas. São Paulo: M. Books, 2010.

TENÓRIO, L. P.; DEBOÇÃ, L. P. O uso das redes sociais pela Administração Pública para informação e criação de espaços digitais de deliberação cidadã. In: CONGRESSO NACIONAL DE MESTRADOS PROFISSIONAIS EM ADMINISTRAÇÃO PÚBLICA, 1., 2016, Curitiba. Anais [...]. Curitiba, 2016.

TERRA, C. F. Usuário-Mídia: nova figura influenciadora para a Comunicação Organizacional? In: CONGRESSO IBERO-AMERICANO DE COMUNICAÇÃO - IBERCOM, 2015, São Paulo, SP. Anais [...]. São Paulo, SP, 2016

TERRA, C. F. Usuário-Mídia: o quinto poder - um estudo sobre as influências do internauta na Comunicação Organizacional. In: CONGRESSO BRASILEIRO CIENTÍFICO DE COMUNICAÇÃO ORGANIZACIONAL E DE RELAÇÕES PÚBLICAS - ABRAPCORP, 3., 2009, São Paulo, SP. Anais [...]. São Paulo: Abrapcorp, 2009.

THOMAZ, G. M. et al. Modelo de monitoreo de las redes sociales para orientar en la toma de decisiones de las Destination Management Organizations. Revista brasileira de pesquisa em turismo. São Paulo, v. 9, n. 2, p. 196-220, maio/ago. 2015.

TORRES, E. F.; MAZZONI, A. A. Conteúdos digitais multimídia: o foco na usabilidade e acessibilidade. Ciência da Informação, Brasília, v. 33, n. 2, p. 152-160, maio/ago. 2004. 
YIN, R. K. Estudo de caso: planejamento e métodos. 3. ed. Porto Alegre: Bookman, 2007. ZÉMOR, P. La Communication Publique. Paris: PUF, 1995. 